\title{
Thermal stability of the ferromagnetic in-plane uniaxial anisotropy of Fe-Co-Hf-N/Ti-N multilayer films for high-frequency sensor applications
}

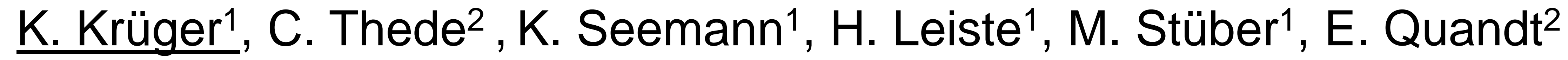

${ }^{1}$ Institute for Applied Materials (IAM-AWP), Karlsruhe Institute of Technology (KIT), Karlsruhe, Germany

2 Institute for Materials Science, Kiel University, Kiel, Germany

kathrin.krueger@kit.edu

Idea: contactless inspection of wear state of surfaces and coatings
Ferromagnetic material

Results

Multilayer films annealed for one hour at $T_{a}=600{ }^{\circ} \mathrm{C}$ in vacuum Temperature-dependent hysteresis loop measurements in

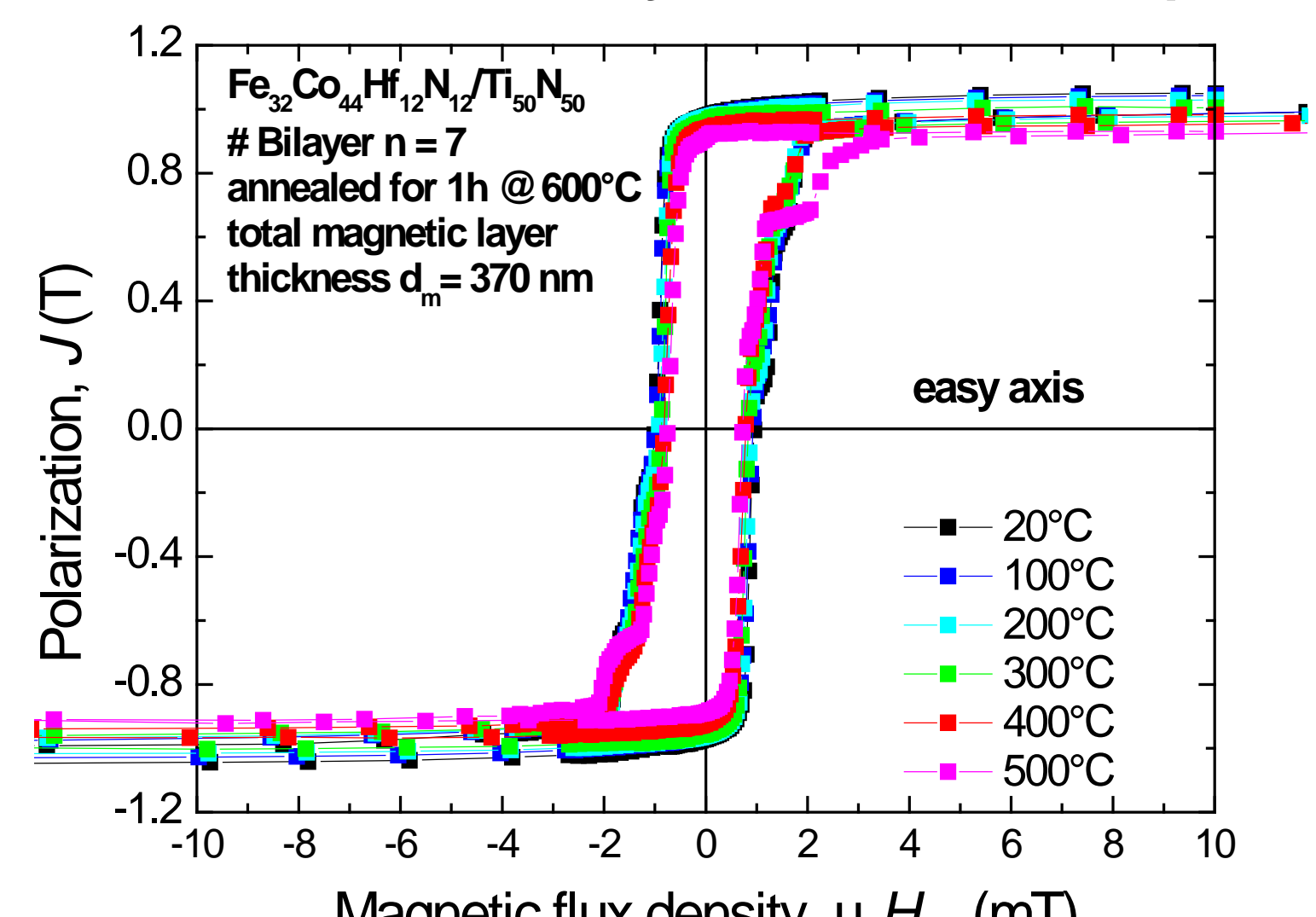

Magnetic flux density, $\mu_{0} H_{\text {ext }}(\mathrm{mT})$

Decrease of coercive field $\mathrm{H}_{c}$ in the hard axis of polarization

Absolute value of $\mu_{0} H_{u}$ decreases slightly from $5 \mathrm{mT}$ at RT to $3.4 \mathrm{mT}$ at $500^{\circ} \mathrm{C}$

Uniaxial anisotropy field $\mu_{0} \mathrm{H}_{\mathrm{u}}$ remains stable in its direction up to $500^{\circ} \mathrm{C}$ within

$\mathrm{Fe}_{32} \mathrm{CO}_{44} \mathrm{Hf}_{12} \mathrm{~N}_{12} / \mathrm{Ti}_{50} \mathrm{~N}_{50}$ multilayer films annealed at $\mathrm{T}_{\mathrm{a}}=600^{\circ} \mathrm{C}$ for $1 \mathrm{~h}$ are suitable

for detecting changes in the resonance frequency up to $500^{\circ} \mathrm{C}$

Kittel resonance formula: $f_{\mathrm{r}}=\frac{\gamma}{2 \cdot \pi} \cdot \sqrt{\left(\mu_{0} H_{u}\right)^{2}+J_{s} \cdot \mu_{0} H_{u}}$

- Decrease in $\mathrm{J}_{\mathrm{s}}$ and $\mu_{0} \mathrm{H}_{\mathrm{u}}$

$>\mathrm{f}_{r}$ decreases with increasing temperature

Experiment: $\mathrm{f}_{\mathrm{r}}$ at $20^{\circ} \mathrm{C}$

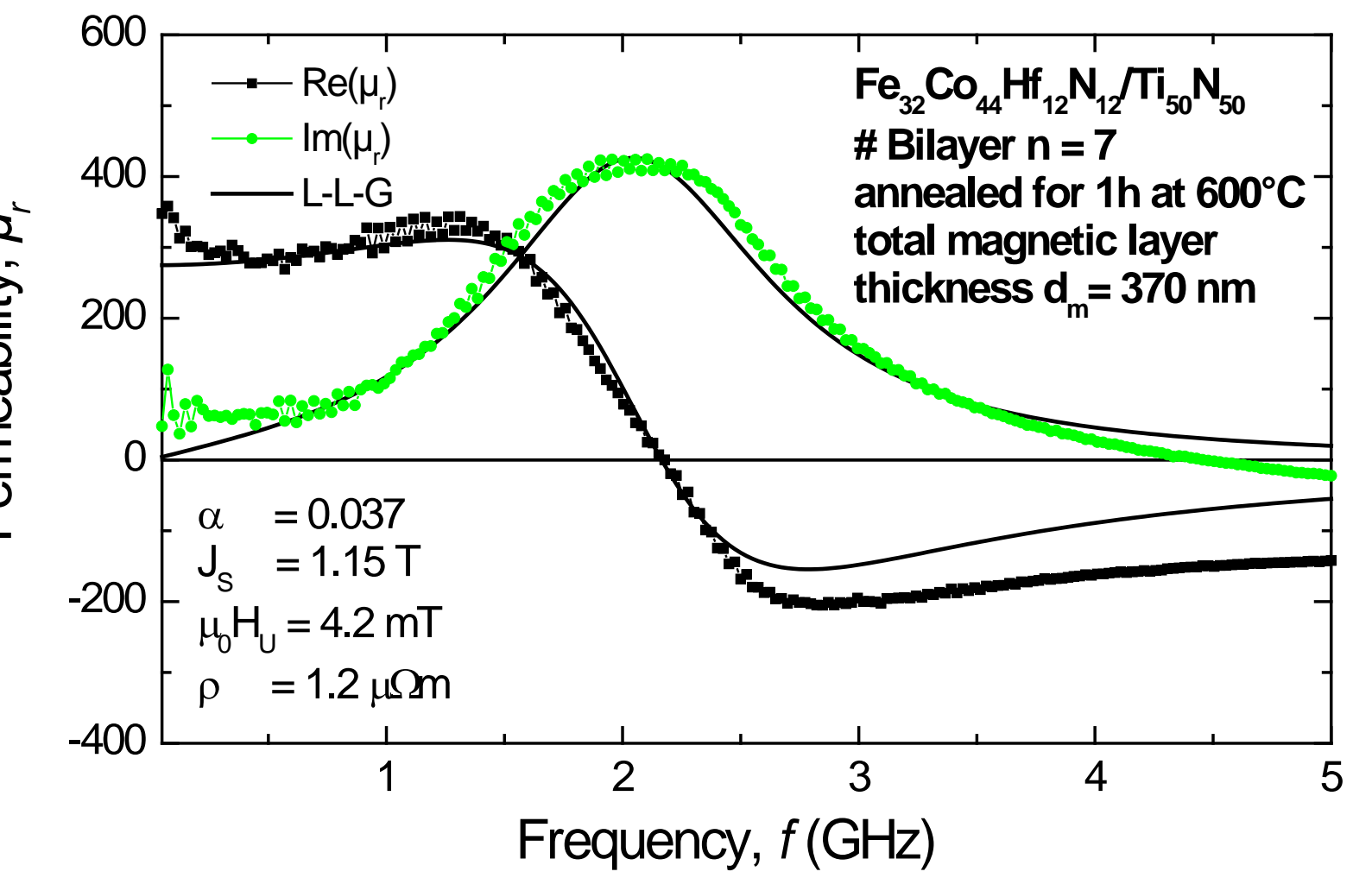

Frequency, $f(\mathrm{GH} Z)$

Dynamic behavior of magnetic moments in a HF-field: eddy-currents [2]

$$
\frac{\partial M}{\partial t}=-\gamma \boldsymbol{M} \times \boldsymbol{H}_{e f f}+\frac{\alpha_{e f f}}{M_{S}}\left(\boldsymbol{M} \times \frac{\partial M}{\partial t}\right)
$$

Clear distinction between easy and hard axis up to $500^{\circ} \mathrm{C}$ Landau-Lifschitz-Gilbert equation (L-L-G) $[1] \quad$ in

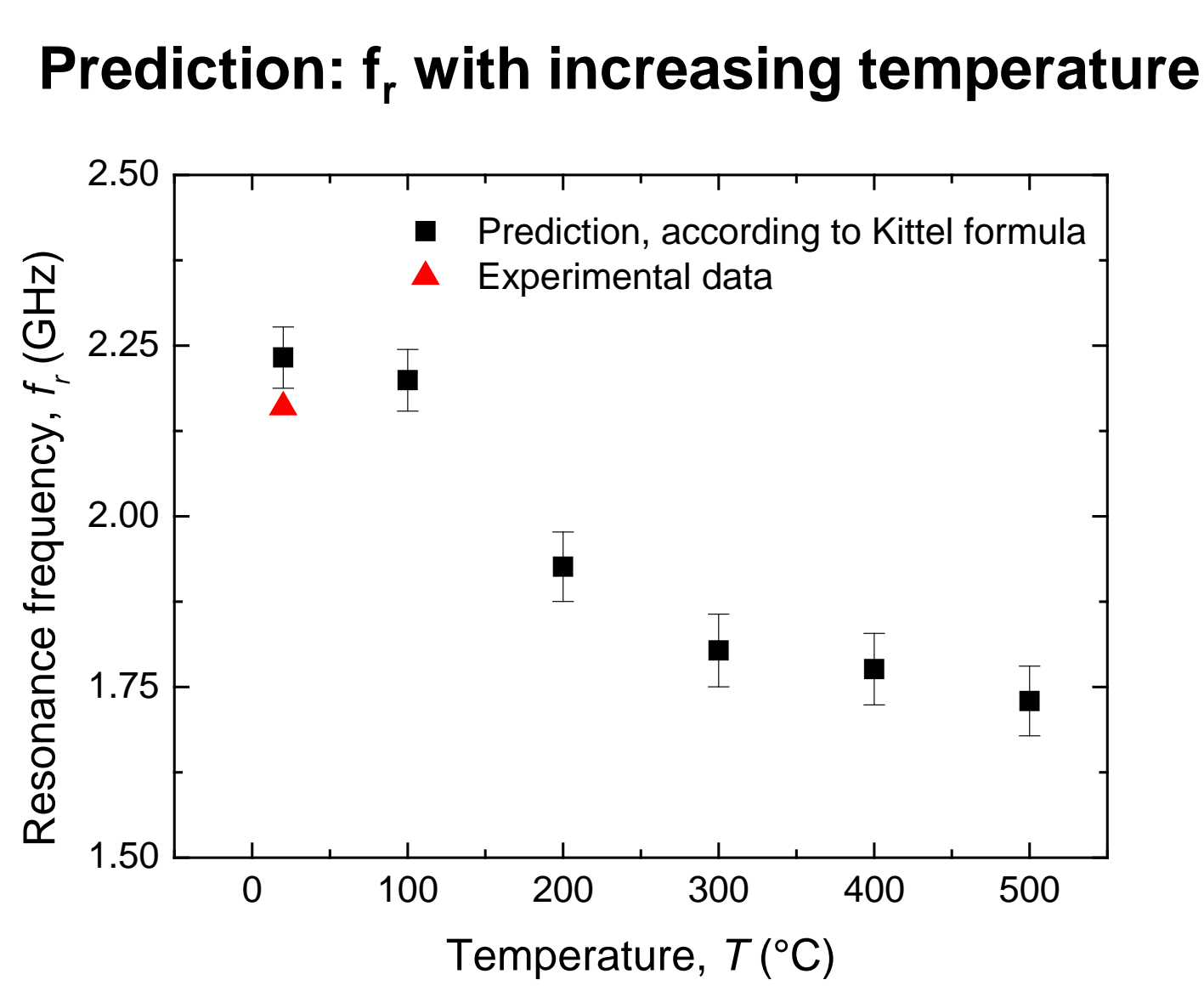

Kittel formula: a decrease in $f_{r}$ is predicted due to the decrease in $\mathrm{J}_{5}(T)$ and $\mu_{0} H_{u}(T)$ with increasing temperature $20^{\circ} \mathrm{C}: \mathrm{f}_{\mathrm{r}}$ was confirmed experimentally Due to thermal fluctuations the damping parameter $\alpha$ is expected to increase
$\mathrm{f}(\mathrm{T})$ will also be affected by $\alpha(\mathrm{T})$
Oxidation process due to heating in air?

Auger electron spectroscopy depth profiles Before heating up to $500^{\circ} \mathrm{C}$

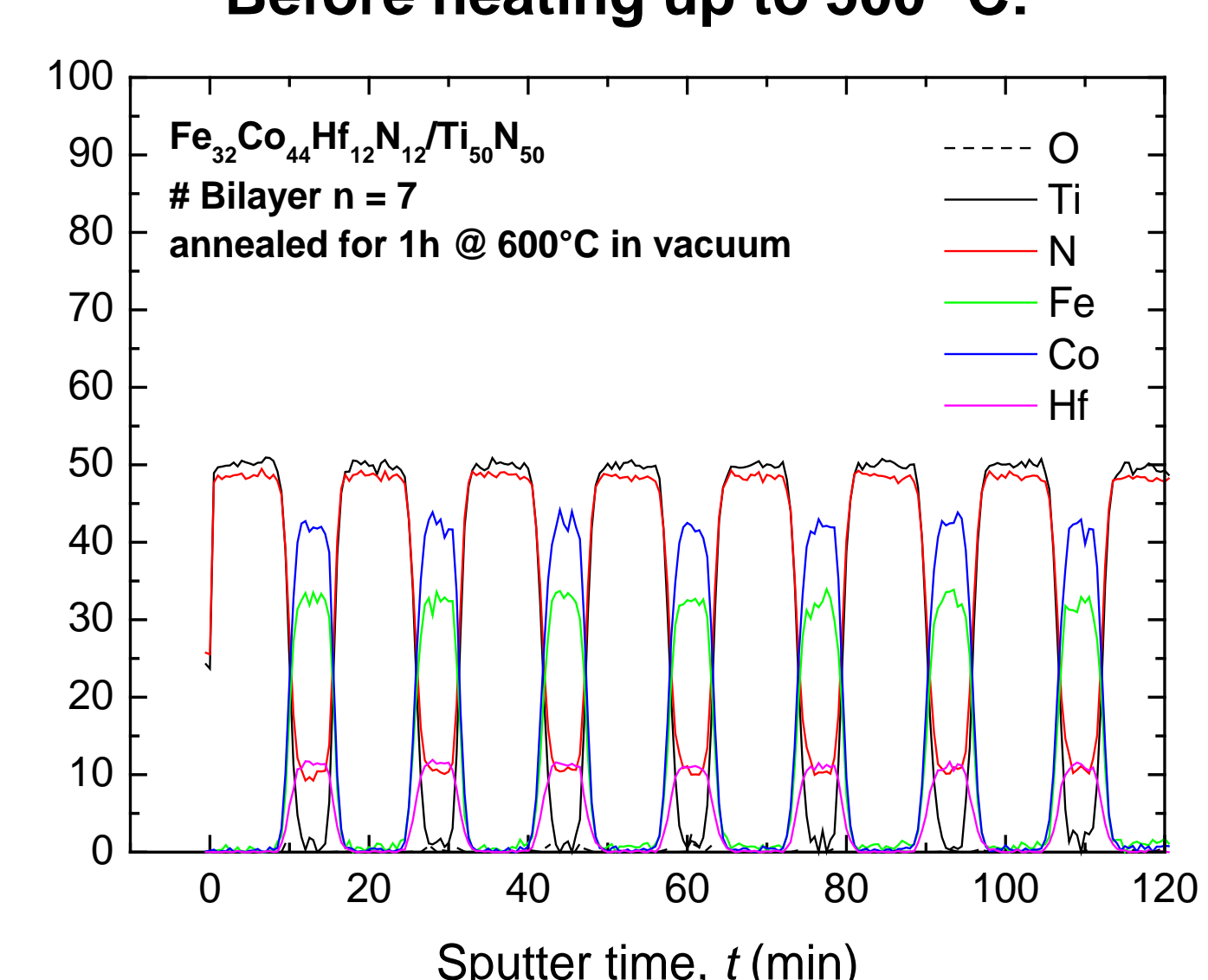

No oxygen in the multilayer annealing in vacuum

After heating up to $500{ }^{\circ} \mathrm{C}$ in air Ar $1 \mathrm{~h}$ during the measurement

$90-\mathrm{Fe}_{32} \mathrm{CO}_{04} \mathrm{HH}_{21} \mathrm{~N}_{27} \mathrm{~N}_{27} \mathrm{~T}_{50} \mathrm{~N}_{50}$

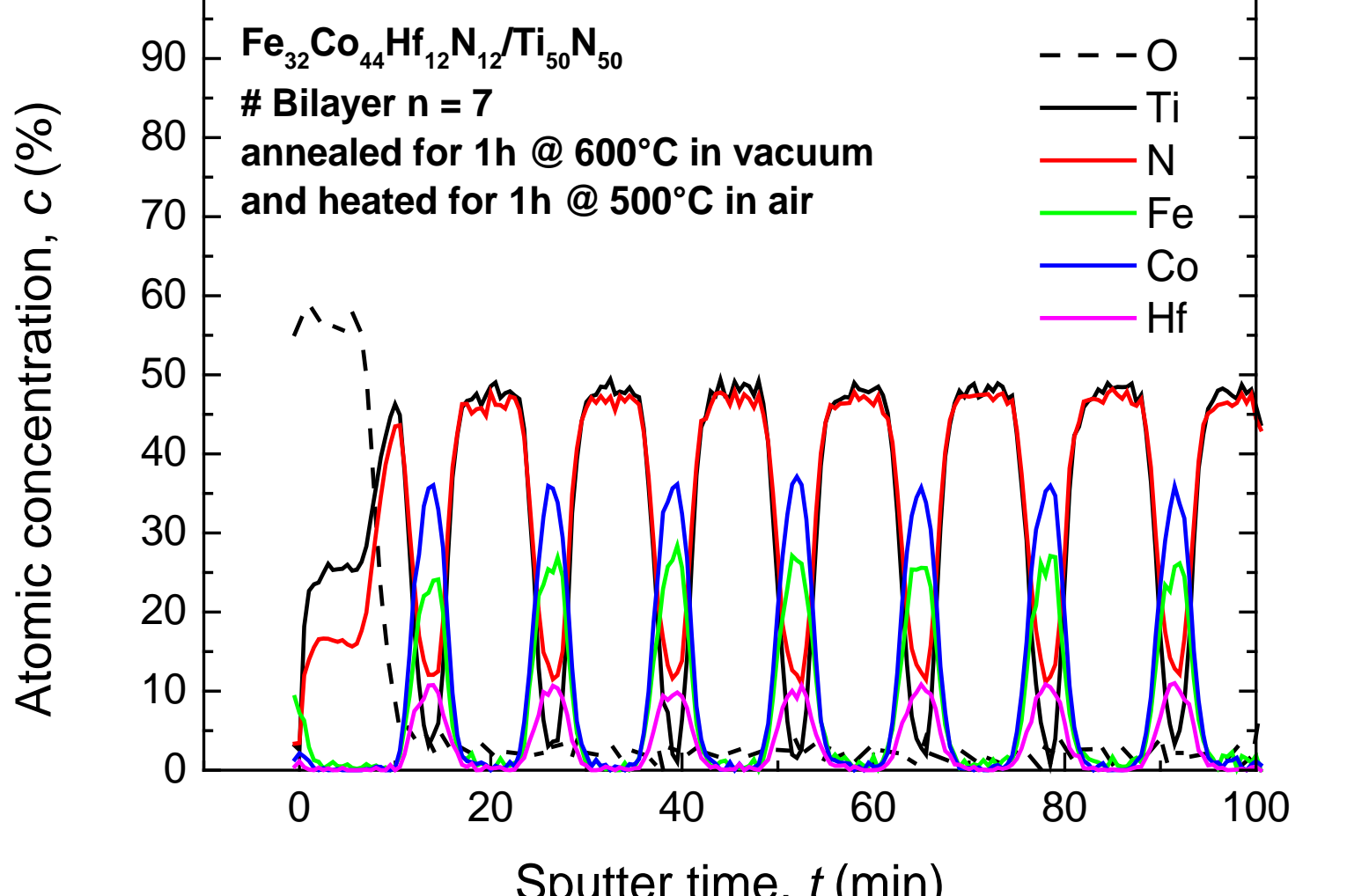

- TiN top layer has oxidized to a large extent to $\mathrm{TiO}_{2}$

A diffusion of the oxygen to the magnetic $\mathrm{Fe}_{32} \mathrm{CO}_{44} \mathrm{Hf}_{12} \mathrm{~N}_{12}$ layer has not occurred ${ }_{32} \mathrm{C}_{44} \mathrm{H}_{22} \mathrm{~N}_{12}$ layer has maintained
Multilayer films annealed for one hour at $T_{a}=400{ }^{\circ} \mathrm{C}$ in vacuum

Temperature-dependent hysteresis loop measurements in asy and hard axis of polarization from RT up to $500^{\circ} \mathrm{C}$ in air

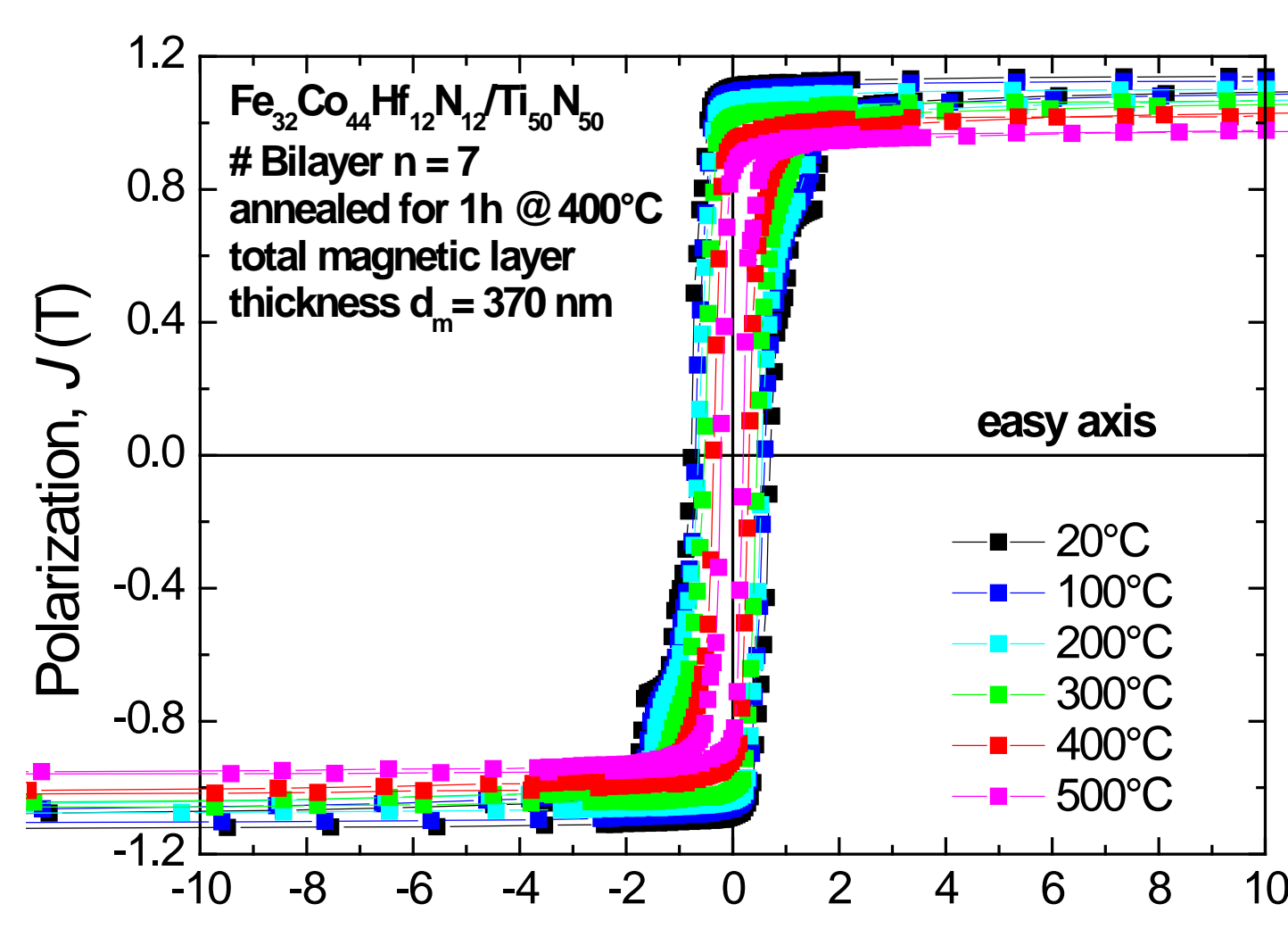

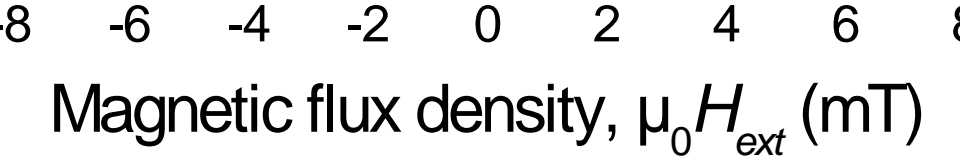

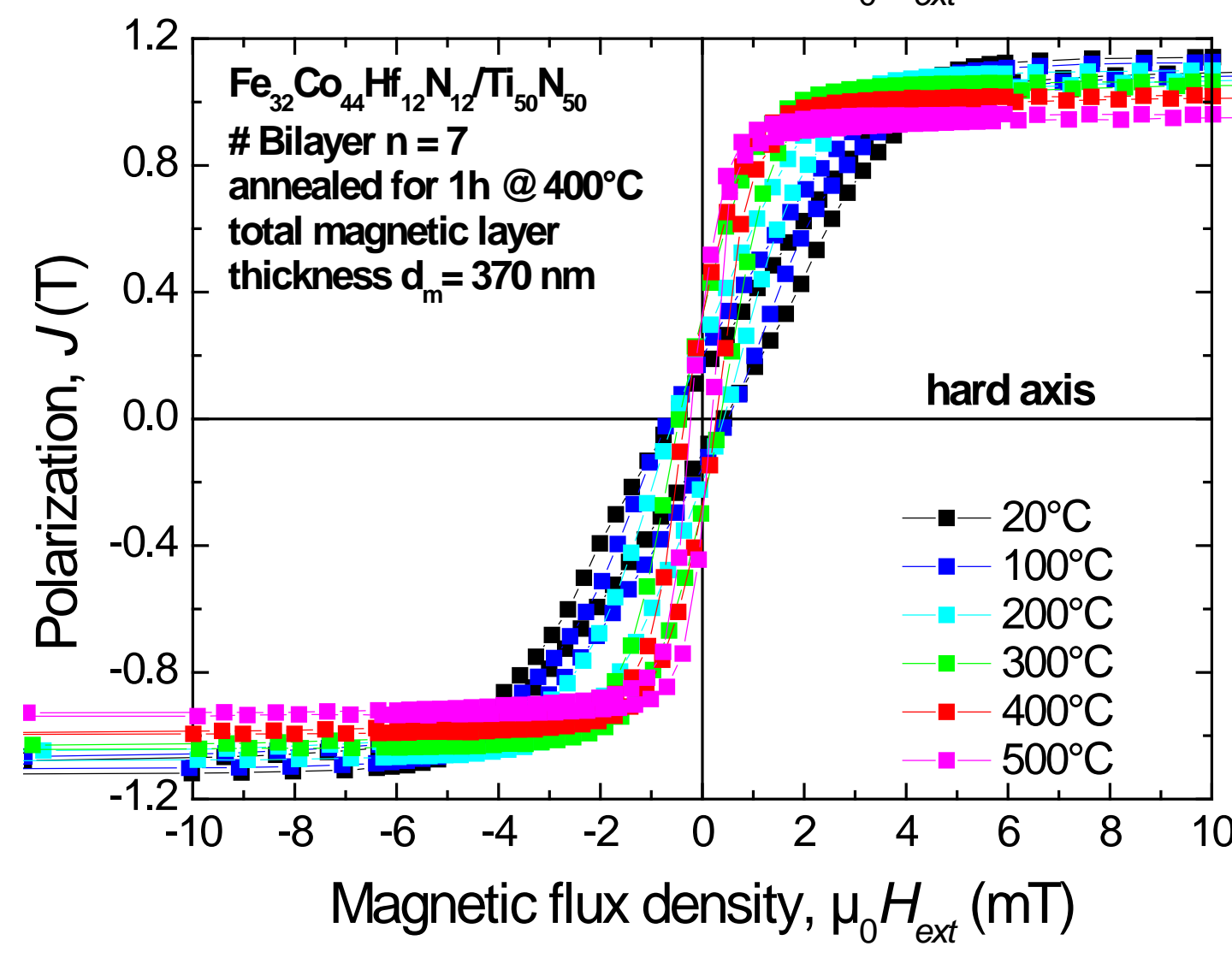

Magnetic flux density, $\mu_{0} H_{\text {ext }}(\mathrm{mT})$

Clear distinction between easy and hard axis at RT

Above $200{ }^{\circ} \mathrm{C}$ the clear distinction starts to vanish

Hysteresis loop measured in the "hard axis" of polarization shows

decreasing uniaxial anisotropy field $\mu_{0} H_{4}$

$\mathrm{Fe}_{32} \mathrm{Co}_{44} \mathrm{Hf}_{12} \mathrm{~N}_{12} / \mathrm{Ti}_{50} \mathrm{~N}_{50}$ multilayer films annealed at $\mathrm{T}_{\mathrm{a}}=400^{\circ} \mathrm{C}$ for $1 \mathrm{~h}$ are less suitable for detecting changes in the resonance frequency

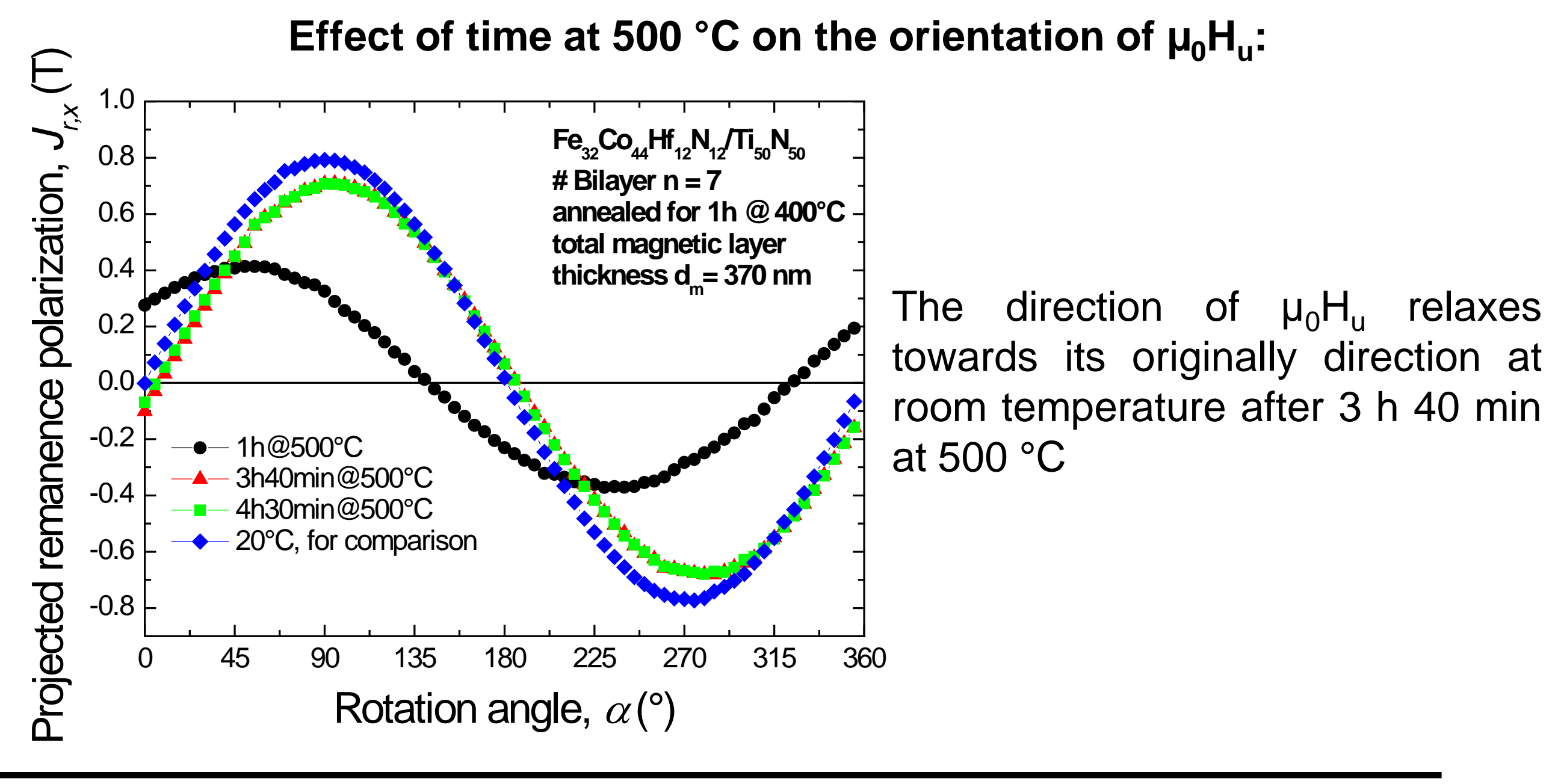

Outlook

\section{Summary}

By annealing the $\mathrm{Fe}_{32} \mathrm{CO}_{44} \mathrm{Hf}_{12} \mathrm{~N}_{12} / \mathrm{Ti}_{50} \mathrm{~N}_{50}$ multilayer films at either $\mathrm{T}_{\mathrm{a}}=400{ }^{\circ} \mathrm{C}$ or $600{ }^{\circ} \mathrm{C}$ for $1 \mathrm{~h}$ in a static magnetic field in vacuum a uniaxial anisotropy field of about $\mu_{0} \mathrm{H}_{\mathrm{u}} \approx 5 \mathrm{mT}$ was induced

The films annealed at $\mathrm{T}_{a}=600^{\circ} \mathrm{C}$ show a temperature stability of $\mu_{0} \mathrm{H}_{u}$ up to $500{ }^{\circ} \mathrm{C}$ at least for $1 \mathrm{~h}$

列

In contrast, the films antis

The change of the uniaxial anisotropy field direction could have been caused by mechanically and thermally induced strain in the magnetostrictive material

Thermally induced strain starts to relax after approximately $3 \mathrm{~h}$ at $500{ }^{\circ} \mathrm{C}$
$\mathrm{Fe}_{32} \mathrm{Co}_{44} \mathrm{Hf}_{12} \mathrm{~N}_{12} / \mathrm{Ti}_{50} \mathrm{~N}_{50}$ multilayer films annealed at $\mathrm{T}_{\mathrm{a}}=400{ }^{\circ} \mathrm{C}$ for $1 \mathrm{~h}$ are less suitable for detecting changes in the resonance frequency above $200{ }^{\circ} \mathrm{C}$
KIT - University of the State of Baden-Wuerttemberg and National Research Center of the Helmholtz Association
[1] T.L. Gilbert, IEEE Trans. Magn. 40 (2004)

[2] K. Seemann, H. Leiste, V. Bekker, J. Magn. Magn. Mater. 278 (2004)
Uniaxial anisotropy field:

Temperature stability 0

Further investigations on the oxidation process at high temperyres

Temperature dependent resonance frequency:

Verification of the thermal stress

Integration of the thermally induced residual stress in the model for $\mathrm{f}_{\mathrm{r}}(\mathrm{T})$ by introducing a magnetoelastic anisotropy Experimental verification of $\mathrm{f}_{\mathrm{r}}(\mathrm{T})$ 